\title{
Assessing the Impact of Urban Roadway Construction Projects through Leveraging Traffic Surveillance Data
}

\author{
Xingguang Chen ${ }^{1,}$, , Lei Chen ${ }^{2, b}$, Hepu Deng ${ }^{1,2, c}$ and Tao Xiang ${ }^{1, d}$ \\ ${ }^{1}$ School of Business, Jianghan Unviersity, Wuhan, P.R.China \\ ${ }^{2}$ School of Business IT and Logistics, RMIT University, Melbourne, Australia \\ acxgsl@126.com, leich@jhu.edu.cn, ${ }^{\mathrm{C} H e p u . d e n g @ r m i t . e d u . a u, ~ d 894157961 @ q q . c o m ~}$
}

\begin{abstract}
Keywords: transport; economic impacts; roadway construction; assessment; big data
Abstract. With the rapid development of urbanization, industrialization and motorization in China, numerous urban roadways construction projects are being planned and implemented. The implementation of such roadways construction projects usually produces a huge impact on the stakeholders and the related community. Adequately assessing the impact of such projects therefore becomes a critical problem that needs to be effectively addressed. This paper presents a novel approach to the assessment of the impact of urban roadway construction projects based on the road traffic networks surveillance data. A case study at Wuhan, China is conducted for demonstrating the effectiveness of the developed approach for evaluating the impact of roadway construction projects. The result shows that the developed approach is effective in assessing the impact of roadway construction projects in urban infrastructure planning.
\end{abstract}

\section{Introduction}

Infrastructure construction plays an important role in the sustainable development of modern cities especially in developing counties. Numerous traffic infrastructure projects usually consist of some distinct components including urban roadway, highway, railway, aviation and shipping. Due to the huge investment involved and the potential impact of such projects on the stakeholders and the related community, adequately assessing the impact of these infrastructure projects has become crucial for justifying the transport infrastructure investment in the world.

The rapid development of the economy and the continuous urbanization in China lead to the implementation of numerous infrastructure projects. A recent study [1] shows that the municipal infrastructure investment in China is expected to be around 7 trillion yuan in the "twelfth five year (2011-2015)" period. The implementation of such a tremendous amount of investment obviously has a huge impact on various stakeholders specific to individual projects as well as the community involved. As a result, adequately assessing the impact of such projects on various stakeholders is critical for the successful implementation of such projects.

This paper presents a novel approach to the assessment of the impact of urban roadway construction projects based on the road traffic networks surveillance data. A case study at Wuhan, China is conducted for demonstrating the effectiveness of the developed approach for evaluating the impact of roadway construction projects. The result shows that the developed approach is effective in assessing the impact of roadway construction projects in urban infrastructure planning.

In what follows, a review of the related literature is presented in Section 2. This is followed by the development of a novel approach for evaluating the impact of infrastructure projects based on the road traffic networks surveillance data in Section 3. A case study is presented in Section 4 for demonstrating the applicability of the developed approach for adequately assessing the impact of infrastructure construction projects. Finally in Section 5, conclusion is given together with the discussion of the future research in this area. 


\section{Related Work}

Much research has been done on investigating the impact of various infrastructure projects from different perspectives. In general, existing research can be approached from three perspectives including the source of impact, the nature of the impact, and the evaluation of the impact. Existing studies from these perspectives are used to help city planners to better justifying the need for various infrastructure construction projects and effectively account for the different investment that the government has committed in a specific period.

The impact source based research focuses on identifying the sources of impact in planning for various infrastructure projects. In this kind of research, various transport infrastructure projects related to different operational regulation or transportation modes are investigated. Often managerial regulation, ground transportation, rail or underground traffic, general transportation infrastructure and special transport modes are evaluated with respect to specific criteria and standards. Alexandersson et al. [2], for example, explore the impact of transport regulation on the roadways construction projects. Gkritza et al. [3] investigate the impact of highway construction projects. Ortega et al. [11] study the impact of new linear transport infrastructures such as high-speed trains [5], urban rail transit systems [8], light rail (tram and light metro) systems [12], the underground metro [13] [14] on the community. Agbelie [7], Korytárová and Hromádka [10], Rahul and Verma [6], and Bella et al. [9] explore the impact of large-scale transportation on various stakeholders.

The impact nature based research concentrates on investigating the specific impact of different infrastructure construction projects on the stakeholders and the community involved. Usually, such impacts from the managerial, economic, social and sustainable perspectives of specific construction projects are explored. Alexandersson et al. [2], for example, investigate the economic impact of long-distance transport services on the society. Gkritza et al. [3] explore the economic, health and environmental impacts of specific infrastructure construction projects. Topalovic et al. [4] focus on the spatial-economic impact of the construction project. Chen and Hall [5] study the impact of the project on the gross domestic product. Rahul and Verma [6] identified the necessity, problems, favorable conditions and economic benefits of non-motorized traffic with respect to sustainability in Indian context. Agbelie [7] relates the implementation of the project with the economic feasibility and potential greenhouse gas savings. Yang et al. [8] presents the analysis of the impacts of urban rail transit system on metropolitan regions. Bella et al. [9] show that there are wider economic impacts of the construction projects. Korytárová and Hromádka [10] discuss which of possible social-economic impacts could be taken in evaluation of particular megaprojects into account. Ortega et al. [11] present a DSS to assess the territorial effects of new linear transport infrastructures. Knowles and Ferbrache [12] examine published and unpublished evidence of economic impacts of modern light rail (tram and light metro) systems in the United Kingdom and globally. Beyazit [13] highlights the necessity of incorporating an understanding of spatio-economic inequalities in the analysis of assessment of the wider economic impacts. Haddad et al. [14] states that there are higher-order economic impacts of the existing underground metro infrastructure.

The impact evaluation based research is based on the assessment of the impact of specific projects on the society. Such studies usually adopt individual normative methods through the use of empirical data. Gkritza et al. [3], Agbelie [7], and Bella et al. [9], for example, use econometric or statistic methods in the evaluation of the impact of the construction project on the society in general. Alexandersson et al. [2], Topalovic et al. [4], Chen and Hall [5], Rahul and Verma [6] , Knowles and Ferbrache [12], and Beyazit [13] apply the case study method to assess the impact of various construction projects on the community involved. Yang et al. [8], Ortega et al. [11], and Haddad et al. [14] adopt the simulation or system analysis method in the assessment of the impact of specific construction projects.

Most of these studies focus on the positive effects of various infrastructure projects from the managerial, economic, social or sustainable perspectives. Little research has been done on the investigation of the negative impact of infrastructure projects on the stakeholders and the community concerned. This shows that the quantitative assessment of economic costs of these negative impacts 
accompanying with urban roadway construction remains a gap in present studies. This paper aims to address this problem through the development of an effective assessment approach employing the torrent of road traffic networks surveillance data.

\section{A Novel Approach}

This section presents a new approach for assessing the negative impacts of infrastructure projects quantitatively incorporating big data. The uniqueness of the proposed approach is on the use of actual real time traffic surveillance data which are collected online. Such an approach can process real data in real time for effectively addressing the inconsistence in the validity and reliability test. It is more attractive than the traditional econometric or statistic approaches in adequately evaluating the impact of such projects on various stakeholders. The advantage of this approach lies in its adaption-ability and flexibility which may be used to tackle the tough problem of negative impacts assessment of infrastructure projects.

Measuring the negative impact of the project, it is an appropriate indicator to consider economic cost. To assess the economic costs induced with roadway construction impacts, a causal relationship is assumed between road construction, traffic status and economic costs. This means that the economic impact of road construction could be evaluated from road networks traffic status. Very evident effects of road construction activities are which may lead to decrease of entire road capacity, i.e., some traffic congestions are due to the road construction activities. Based on these considerations, an overview of the study framework is presented in Fig. 1.

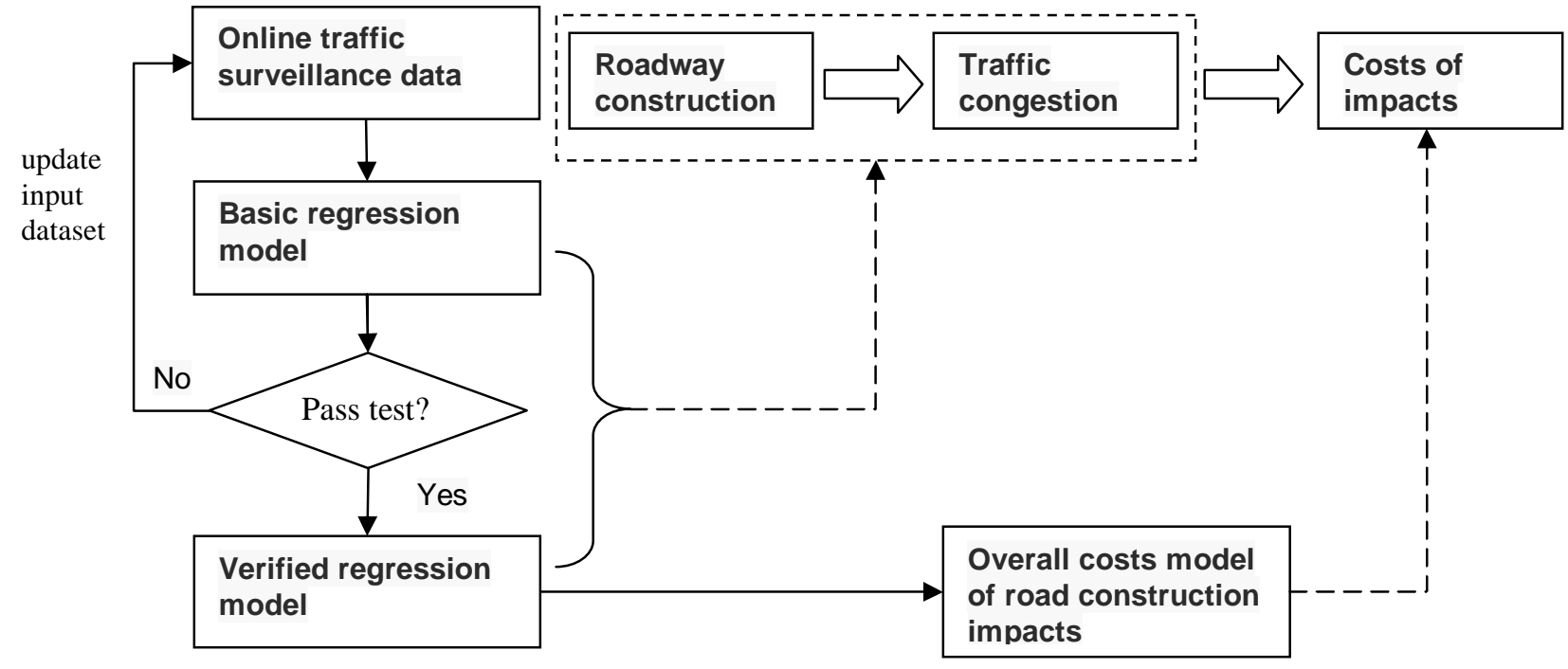

(1) The basic regression model (BRM) is:

Fig. 1. A Study Framework

$S_{i}=\beta_{0}+\beta_{1} L_{i}+\beta_{2} D_{i}$.

(1)

$S_{i}$ is response variable indicates congestion status of specific regions or roads, $L_{i}$ and $D_{i}$ are independent variables denote distance of constructing roadway and planned project duration respectively. $\beta_{0}, \beta_{1}$ and $\beta_{2}$ are parameters to be estimated.

(2) The verified regression model (VRM) is:

$\bar{S}_{i}=\bar{\beta}_{0}+\bar{\beta}_{1} L_{i}+\bar{\beta}_{2} D_{i}$.

Response variable $\bar{S}_{i}$, independent variables $L_{i}$ and $D_{i}$ have the same meanings as Eq. 1, while $\bar{\beta}_{0}$, $\bar{\beta}_{1}$ and $\bar{\beta}_{2}$ are regression coefficients already conformed with the statistic test.

(3) The overall costs model of road construction impacts (OCM) is:

$\mathrm{TC}_{\mathrm{k}}=\Sigma_{\mathrm{i}} \mathrm{C}_{\mathrm{i}}=\Sigma_{\mathrm{i}}\left(\overline{\mathrm{S}}_{\mathrm{i}} * \mathrm{~L}_{\mathrm{i}} * \mathrm{D}_{\mathrm{i}}\right)$.

$\mathrm{TC}_{\mathrm{k}}$ indicates total costs of $k$ th construction region we want to get finally, where summation notation " $\Sigma$ " indicates sum up all roads belong to $k$ th construction region. 


\section{Case Study}

We use road traffic networks surveillance data of Wuhan City, China by employing Gaode online map [15] to carry out our analysis. Original data are collected including ten administrative districts of Wuhan City ,i.e., Jiang'an district, Jianghan district, Qiaokou district, Dongxihu District, Wuchang district, Hongshan district, Qingshan district, Jiangxia district, Hanyang district and Caidian district. Overall, there are sixty four roadways under construction up to the middle of December, 2015. We take these 64 roadways as our input sample set, accordingly, for every sample we get its important project information involves start and stop position, total distance, planned project duration, respective regional and average index of congestion. It's worth noting that we think average index of congestion is a good indicator which reflecting the congestion status of specific region or road. We have found three outliers in the check phrase accounting for basic regression model, therefore sixty one roads data are used to carry out the analysis later. For the limitation of space, we only list administrative district data whose descriptive features are demonstrated in Fig. 2 and Table 1 respectively.

Table 1 Descriptive Statistics of District Data

\begin{tabular}{|l|c|c|c|}
\hline District & Distance(km) & $\begin{array}{c}\text { Duration(hundred } \\
\text { days) }\end{array}$ & $\begin{array}{c}\text { Average } \\
\text { congestion } \\
\text { index }\end{array}$ \\
\hline Wuchang & 1.15 & 20.27 & 1.5 \\
\hline Hongshan & 33.5 & 55.47 & 1.37 \\
\hline Jianghan & 3.38 & 14.34 & 1.45 \\
\hline Jiang'an & 3.29 & 14.62 & 1.4 \\
\hline Hanyang & 2.25 & 7.13 & 1.37 \\
\hline Qiaokou & 2.54 & 3.74 & 1.35 \\
\hline Qingshan & 0.05 & 0.83 & 1.24 \\
\hline Caidian & 3.69 & 4.02 & 1.24 \\
\hline Dongxihu & 29.86 & 6.33 & 1.21 \\
\hline Jiangxia & 5.88 & 18.1 & 1.23 \\
\hline
\end{tabular}

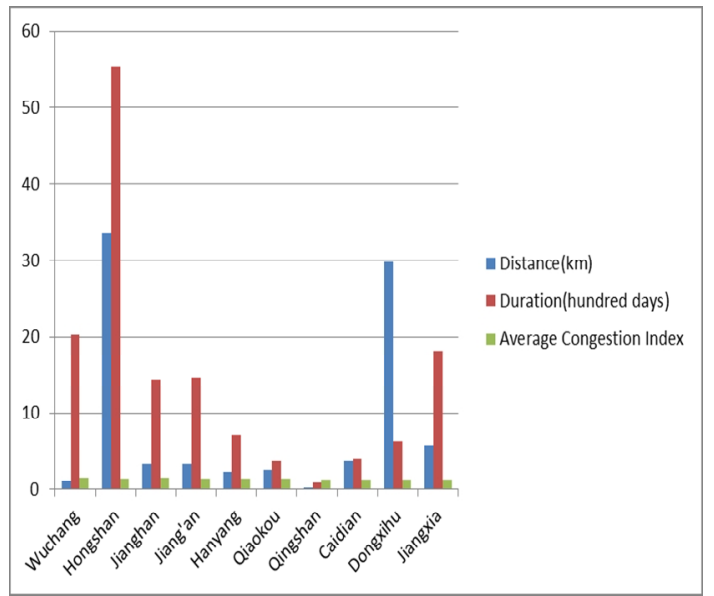

Fig. 2. Comparison of Districts

Fig. 3 and Table 2 show the result of using the proposed approach for evaluating the impact of roadways construction projects. 


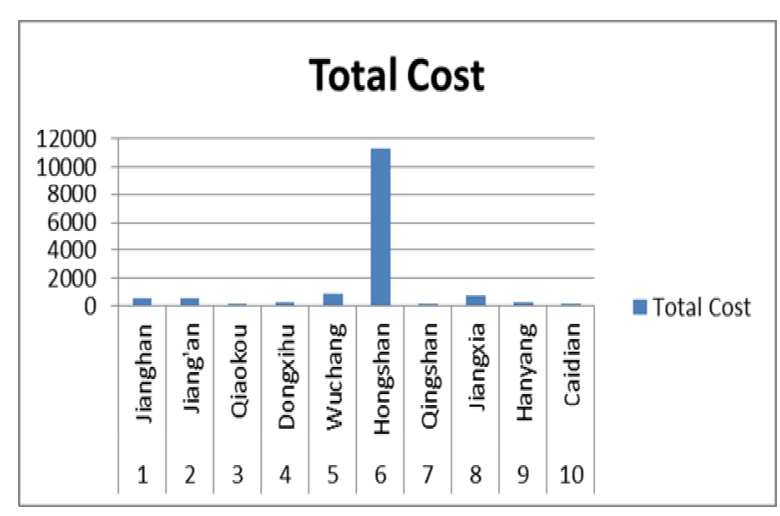

Fig. 3. Comparison of Impacts Cost
Table 2 Total Cost of Impacts

\begin{tabular}{|c|l|l|}
\hline No. & District & Total Cost \\
\hline 1 & Jianghan & 491.5038374 \\
\hline 2 & Jiang'an & 512.2236604 \\
\hline 3 & Qiaokou & 141.9165032 \\
\hline 4 & Dongxihu & 214.261155 \\
\hline 5 & Wuchang & 879.6354175 \\
\hline 6 & Hongshan & 11286.89387 \\
\hline 7 & Qingshan & 0.8177575 \\
\hline 8 & Jiangxia & 696.3314633 \\
\hline 9 & Hanyang & 182.5125475 \\
\hline 10 & Caidian & 168.3140818 \\
\hline
\end{tabular}

\section{Conclusion}

Increasingly constructing speed and size of infrastructure are leading to serious challenges on economic, social, environmental and ecological sustainability especially for many developing countries. In this paper a novel assessment approach of constructing impacts is proposed leveraging enormous surveillance data generating from ubiquitous traffic sensor networks. The simplicity and effectiveness make this approach a favorable alternative solution contrast on the traditional methods, thus more applications may be considered employing our presented approach.

\section{Acknowledgements}

This work was financially supported by the National Natural Science Foundation of China (Grant No. 71471084, 71371094).

\section{References}

[1] Information on http://www.zgszjs.com/news/bencandy.php?fid=80\&id=3694

[2] G. Alexandersson, S. Hultén, N. Fearnley and F. Longva: Research in Transportation Economics Vol. 29 (2010), p. 212

[3] K. Gkritza, K.C. Sinha, S. Labi and F.L. Mannering: The Annals of Regional Science Vol. 42 (2008), p. 545

[4] P. Topalovic, J. Carter , M. Topalovic and G. Krantzberg: Social Indicators Research Vol. 108 (2012), p. 329

[5] C.-L. Chen and P. Hall: Journal of Transport Geography Vol. 24 (2012), p. 89

[6] T.M. Rahul and A. Verma: Research in Transportation Economics Vol. 38 (2013), p. 22-34.

[7] B.R.D.K. Agbelie: Transport Policy Vol. 35 (2014), p. 304

[8] Y. Yang, P. Zhang and S. Ni: Transportation Research Procedia (Mobil. TUM 2014 "Sustainable Mobility in Metropolitan Regions") Vol. 4 (2014), p. 521

[9] K.Bella, S.P. Souza, B. Strogen and D. Zilberman: Energy Procedia (The 6th International Conference on Applied Energy - ICAE2014) Vol. 61 (2014), p. 2371

[10] J. Korytárová and V. Hromádka: Procedia-Social and Behavioral Sciences (27th IPMA World Congress) Vol. 119 (2014), p. 495 
[11] E. Ortega, I. Otero and S. Mancebo: TITIM GIS-tool: Expert Systems with Applications Vol. 41 (2014), p. 7641

[12] R.D. Knowles and F. Ferbrache: Journal of Transport Geography, http://dx.doi.org/10.1016/j. jtrangeo.2015.09.002 (2015), in press.

[13] E. Beyazit: Journal of Transport Geography Vol. 45 (2015), p. 12

[14] E.A. Haddad, G.J.D. Hewings, A.A. Porsse, E.S.V. Leeuwen and R. S. Vieira: Transportation Research Part A Vol. 73 (2015), p. 18

[15] Information on http://tp.amap.com 